\title{
Properties and Medical Applications of Biocompatible Polyamide in Additive Manufacturing
}

\author{
DAN IOAN STOIA ${ }^{1}$, COSMINA VIGARU ${ }^{*}$, CARMEN OPRIS ${ }^{2}$, MARIUS VASILESCU ${ }^{*}$ \\ ${ }^{1}$ Politehnica University of Timisoara, Department of Mechanics and Strength of Materials, 1 Mihai Viteazul Av., 300222 , \\ Timisoara, Romania \\ ${ }^{2}$ Politehnica University of Timisoara, Department of Materials and Manufacturing, 1 Mihai Viteazul Av., 300222, Timisoara, \\ Romania \\ ${ }^{3}$ University Politehnica of Bucharest, Department of Metallic Materials Science, Physical Metallurgy, 313 Splaiul \\ Independenţei, J Building, 060042, Bucharest, Romania
}

\begin{abstract}
The paper presents the structural and dimensional differences of rectangular shape samples manufactured by selective laser sintering (SLS) according to three process sinterization energies. In this study we determine the geometrical and structural characteristics of biocompatible PA2200 polyamide manufactured at a low energy density E1, and intermediate value E2 and a high energy density E3. Relaying on these results, four custom-made medical parts have been built using biocompatible polyamide PA2200 powder, in order to evaluate their performances.
\end{abstract}

Keywords: additive manufacturing, polyamide, selective laser sintering, biocompatibility, microscopy

\section{Introduction}

Combining the geometrical versatility of additive manufacturing (AM) process with biocompatible polymers opens wide possibilities in custom manufacturing of complex shape structures designed for human body. The polymeric materials can be used as bone substitutes while additive technologies allow constructing the appropriate shape and functional characteristics of a biological structure [1,2]. The custom implant and prosthesis are continuously developing due to additive manufacturing technologies which allows constructing mechanical parts that mimics the local anatomy of a patient starting directly form computer tomographic images [3,4]. Beside these the ready to use parts, the AM models successfully serves as disposable tools used in surgery or visualization elements for surgeons preoperative planning [5-9].

Independent on the type of AM technology, the dimensional accuracy [10, 11], the mechanical properties $[12,13]$ and the material used [14, 15] represents challenging research issues. The inconsistencies in shape, size and mechanical properties are associated with a series of process parameters that are very specific to each technology [16-19].

The characterization of the products from all engineering perspectives is critical, especially because there is no standardization related with these technologies [20-22]. Many authors focus their work on process dependent properties of AM products. The process parameters are in large number and they play a great role in geometrical and mechanical properties particularly on selective laser sintering (SLS) [2325]. Some of these are controllable: laser power, temperatures, position and orientation of the samples, layer thickness, material, scanning strategies; while other are difficult to control and estimate during the process: humidity, powder degradation, temperatures gradients in powder, bulk density, contractions at cooling, electrostatic charging and compaction rate.

The geometric assessment and structure microscopy were used by some authors in order to characterize the parts resulted from AM process. Some authors work on geometrical characterization of samples obtained at different orientations and/or energy density by measuring the size and shape and inspecting the surface and internal cross sections by stereomicroscopy [26, 27]. The inconsistency in shape size and properties of SLS polymers caused by the uneven temperature distribution in the powder volume were studied [28]. Other authors put efforts in identification of mechanical properties of poly - 
amide according to some process variables, in both tensile and bending tests [29-31]. Correlations between process parameters and real properties of the parts obtained by mechanical testing (tensile, compression, bending) and also geometric shape and tolerances were also studied [32-34]. The consistencies of the results were point out using ANOVA statistics underlining the possibility of adjusting the laser exposure as long as the energy density delivered in the powder layer is optimal [35].

The aim of this study was to determine the geometrical and structural characteristics of biocompatible PA2200 polyamide manufactured by SLS additive process under three different manufacturing conditions: a low energy density E1, and intermediate value E2 and a high energy density E3. Excepting the energy density, the other AM parameters remains constant in order to observe the influence of a single variable. The novelty of the study consists in identification of a manufacturing parameter for PA2200 biocompatible polyamide manufactured by SLS, that will lead to better dimensional stability and internal structure. Based on these findings, four custom-made medical parts were built in order to evaluate their performances.

\section{Materials and methods}

\subsection{Materials}

The material used in manufacturing samples and medical applications was polyamide PA2200 in powder form. This is a multipurpose material developed by Electro Optical Systems (EOS) [36] and which exhibit high strength and stiffness, good chemical and long-term stability, high detail resolution, good biocompatibility according to EN ISO 10993-1[37] and food contact approval in compliance with the EU Plastics Directive 2002/72/EC. In the powder form it possesses the following characteristics: average grain size $56 \mu \mathrm{m}$ according to ISO $13320-11$; bulk density of $0.45 \mathrm{~g} / \mathrm{cm}^{3}$ according to EN ISO 60 ; melting point $172-180^{\circ} \mathrm{C}$ according to EN ISO 11357-1 [38]. The mechanical properties of PA2200 that are highly influenced by the process parameter [39-41]

\subsection{Methods}

The AM process was conducted on laser machine EOS Formiga P100 (Electro Optical Systems $\mathrm{GmbH}$, Germany). The machine uses a $30 \mathrm{~W} \mathrm{CO}_{2}$ laser for sintering the powder particles and two electrical heating sources to rise up the temperature of the powder in the softening range, in such way that the lase only give the additional energy required for particle bonding. The machine and software preparation consist in virtual positioning of the parts in the building envelope and building envelope setup. In this stage, the process parameters were set to the following values: building chamber temperature $169.5^{\circ} \mathrm{C}$; Removal chamber Temperature $152^{\circ} \mathrm{C}$; Layer thickness $0.1 \mathrm{~mm}$; Uniform scaling factors $2.2 \%$; Beam offset $0.15 \mathrm{~mm}$. The scan spacing $(s)$ was $0.25 \mathrm{~mm}$ constant while the laser power $(P)$ and laser beam velocity $(v)$ were set to $24.5,22.8$ and $21.8 \mathrm{~W}$ respectively 1500,2000 and $2500 \mathrm{~m} / \mathrm{s}$. The energy densities resulted from these combinations of power, beam velocity and scan spacing were: $\mathrm{E} 1=0.065 \mathrm{~J} / \mathrm{mm}^{2} ; \mathrm{E} 2=0.045 \mathrm{~J} / \mathrm{mm}^{2} ; \mathrm{E} 3=0,035 \mathrm{~J} / \mathrm{mm}^{2}$ (Eq. 1 ).

$$
\mathrm{E}\left[\mathrm{J} / m m^{2}\right]=\frac{P}{v \cdot s}
$$

The sample geometry of $60 \times 22 \times 12 \mathrm{~mm}$ rectangular section beam and the medical custom parts were designed in SolidWorks 2013. Fifteen rectangular section samples were manufactured for each energy density: E1, E2 and E3.

The investigations consist of geometrical measurements, weighting and microscopic investigations. The measurements were acquired using a digital caliper having a resolution of $0.02 \mathrm{~mm}$. The dimensional error was computed taking into account the nominal dimension of the sample on each axis (Eq. 2).

$$
\text { error }[\%]=\left|\frac{d_{\text {meas }}-d_{\text {nom }}}{d_{\text {nom }}}\right| \cdot 100
$$


The optical microscopy was conducted on Olympus BX51M microscope at a magnification of 100 and 200X respectively, the acquired images being analyzed using Analysis 5.0 software. Every sample was weighted using $500 \mathrm{~g}$ Kerrn balance having a resolution of $0.001 \mathrm{~g}$. Based on mass results (M) and volume $(1 \times \mathrm{b} \times \mathrm{h})$, the volumetric mass density (Eq. 3) was computed for each process energy.

$$
\rho\left[\mathrm{g} / \mathrm{cm}^{3}\right]=\frac{M}{l \cdot b \cdot h}
$$

\section{Results and discussions}

At the end of the manufacturing process, the samples were let to cool down inside the machine for 1 day. The parts extraction and coding were done in order to keep the connection between the part position in the building envelope and their dimensions, weight and structure. The location of each sample was coded as: front, middle or back, where the front positioning was considered the vicinity of the machine's door, while back is the far plane. The post-processing was conducted prior to any investigation and it consists in air blowing for removing the excess non-sintered powder.

The measurements on every direction were conducted 3 times and an average value was saved. The samples were individually weighted and relying on size and mass, the volumetric mass density was computed. In the Figure $1 a, b$ and $c$, the dimensional error of each dimension is represented, according to the parts position in the machine.

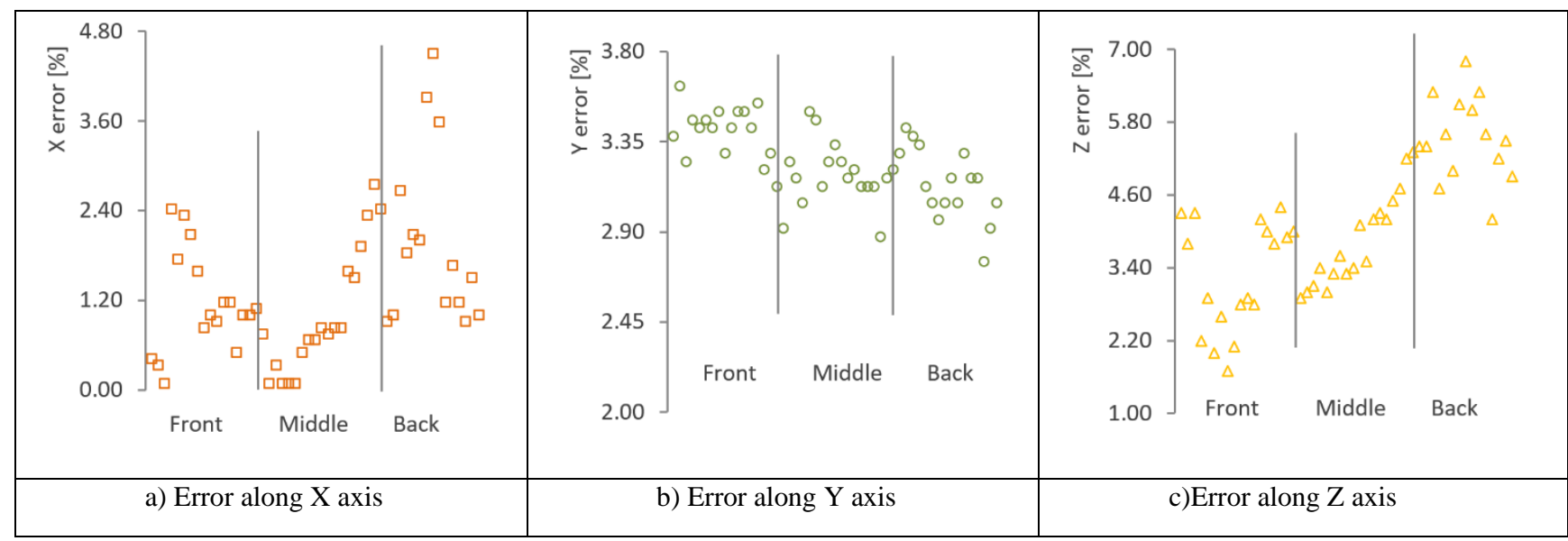

Figure 1. Linear errors according to the sample positions in the building envelope

The highest recorded error was for linear dimension on $\mathrm{Z}$ direction of the machine. This behavior is rather common in additive manufacturing since the $\mathrm{Z}$ direction is the direction of the layer deposition and part growing. The $\mathrm{X}$ and $\mathrm{Y}$ errors are more reduced in values due to the symmetry in the sinterization process (X-Y laser traces). From the position point of view, differences in dimensional accuracy are associated with the front-back direction of the machine. It appears that samples that grows in the middle position of the building plane are more stable from dimensional perspective. This phenomenon may be explained by the heat transfer inside the envelope. The parts that are surrounded by a large volume of powder (middle parts) are cooling much slower and for this reason their dimensions are more stable.

The volumetric mass densities of the samples according to the energy used in the sinterization process is depicted in the Figure 2. As it can be observed, the highest energy E1 lead to the highest volumetric mass density of the samples, around $0.85 \mathrm{~g} / \mathrm{cm}^{3}$ while the lowest energy E3 conducts to a much lower value, of about $0.65 \mathrm{~g} / \mathrm{cm}^{3}$. Taking into consideration that all mechanical properties are directly connected with the structure and therefor with density, the energy providing the higher volumetric mass density is the one that leads to superior mechanical properties. The low standard deviation indicates a good structural stability in all energies that been used. 


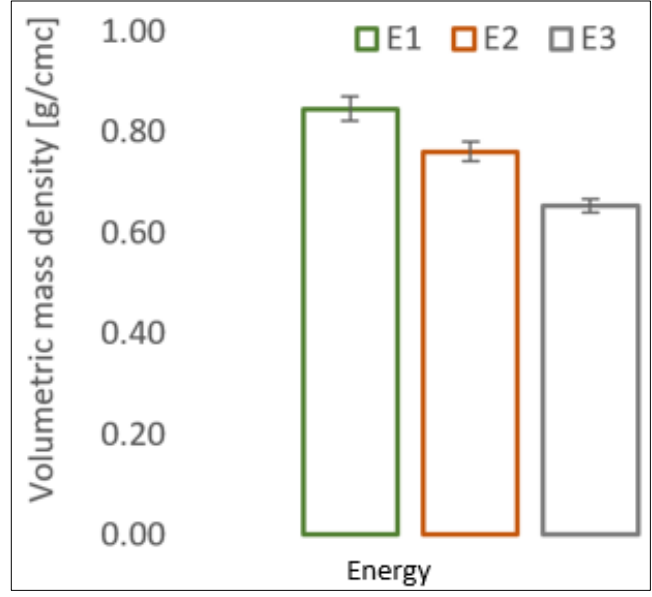

Figure 2. Volumetric mass density according to process energy

The microscopic images AM polyamide structure were taken at a magnification of 100 and 200X. In the Figure $3 a-f$, the structure is presented for all three energies. In images, the sinterization aspect of the structures shows a partial coalescence of the particles no matter the energy value. The bonds between the powder particles instead are in the shape of small bridges proportional in size with the energy value.

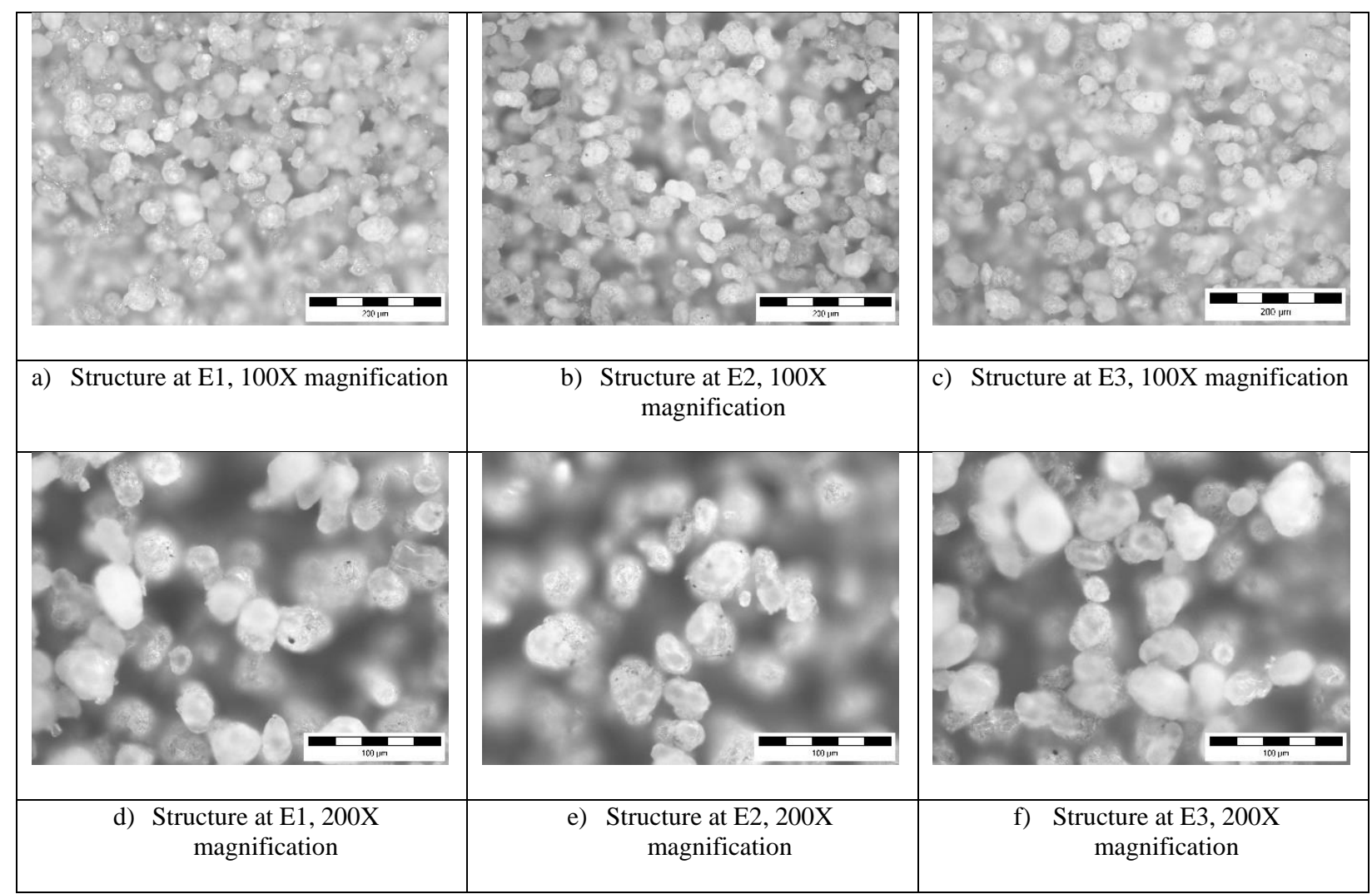

Figure 3. Microscopic images of the PA2200 structure acording to energy density

Although the porosity cannot be measured, by overlapping color filters on the images, a difference between particles and voids can be objectively measured. In Figure 4, the overlapping color masks are presented. Here, the red color was applied on highly focused particles while the blue color on particles originated in the deeper planes of the structure. A percentual result of partially coalesced particles and voids is presented in the Figure 5. The sum of percentages of particles and voids for one energy is not $100 \%$ because of transitional area between sharp focused particles and deep blurred particles (voids) that cannot be associated with any of the two colors. In other words, this can be considered the error and the limitation of this method. Anyway, the presence of bonded particles for E1 is around 20\% larger than 
for $E 3$. This investigation confirms the structural differences and sustains the differences determined by computing the volumetric mass density.

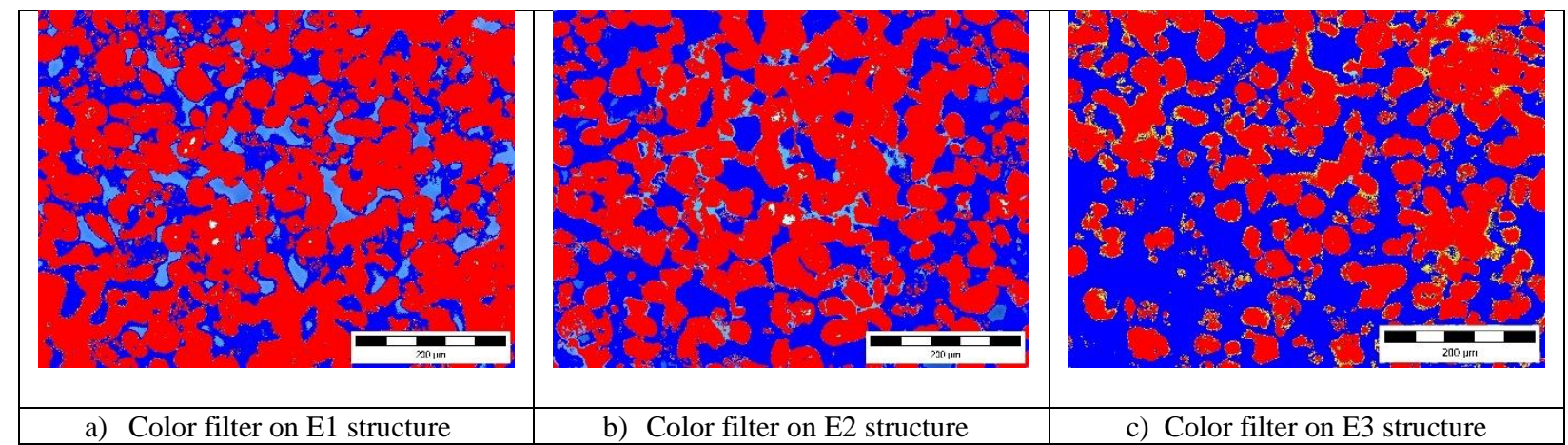

Figure 4. Color filters applied on samples microscopic images

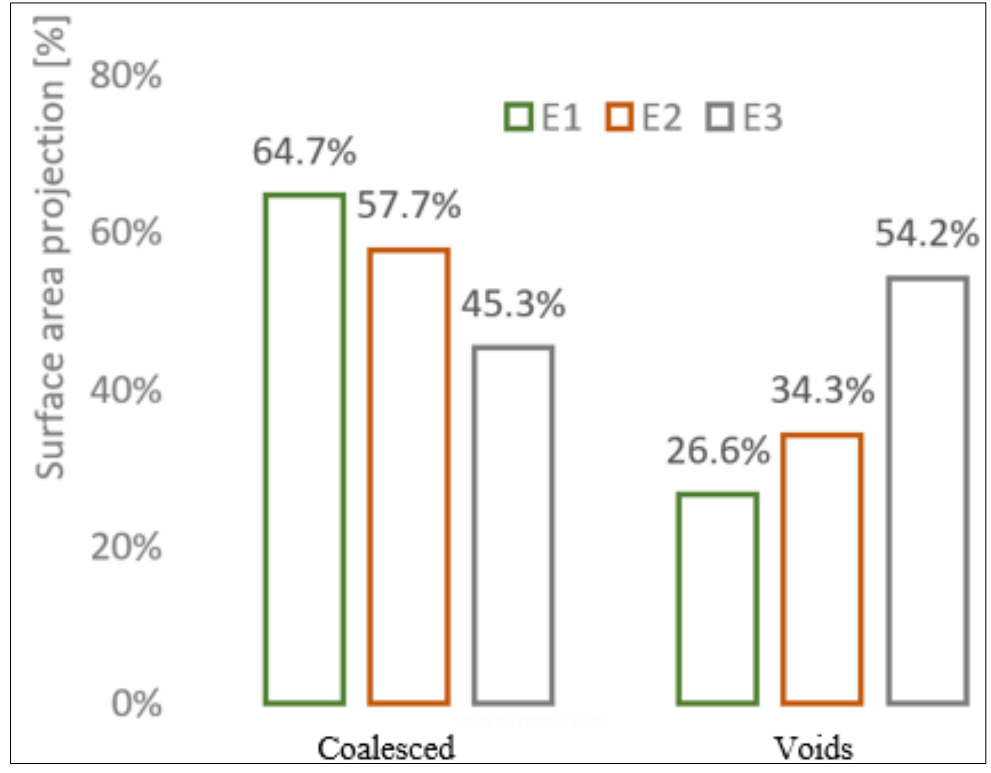

Figure 5. Percentages of partial coalesced particles and voids according to energy

In the next phase of the study, based on the dimensional and structural properties determined, four prototypes belonging to the medical field were built. The custom designs were chosen in such a way to cover a large variety of shapes at comparable sizes. In Figure 6 the pats manufactured from PA2200 using E1 energy are presented: a) depicts a fusion plate implant designed for cervical vertebrae fusion; b) lattice structure for bone reconstruction and/or substitution; c) intervertebral cage designed to recreate the anatomical wedge shape of the lumbar intervertebral discs; d) a prototype of short stem one component hip prosthesis. 


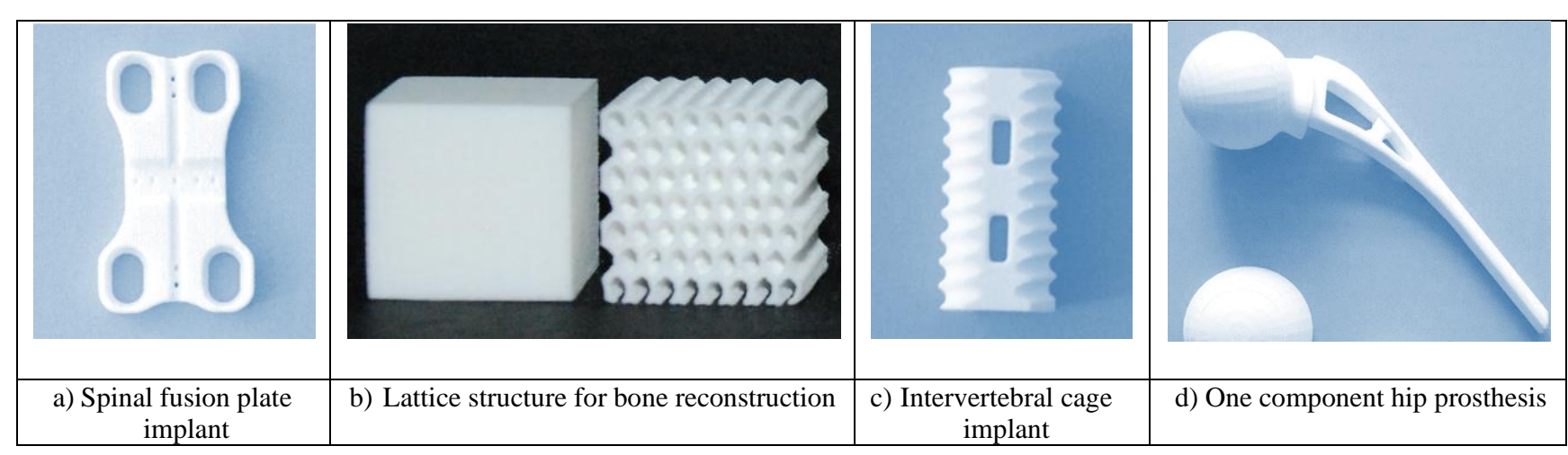

Figure 6. Medical applications of biocompatible polyamide, by SLS

\section{Conclusions}

The paper presents the dimensional accuracy, volumetric mass density and internal structure and of polyamide PA2200 manufactured by selective laser sintering using three energy densities E1, E2 and E3. Based on these findings, four custom made medical parts that were built in order to evaluate their performances.

The dimensional accuracy of laser sintered polyamide is dependent on process energy and parts position on the building environment. High dimensional errors are recorded for vertical direction of the samples comparing to the $\mathrm{X}-\mathrm{Y}$ directions. The volumetric mass density and structure are directly dependent on energy density used in the sinterization process. Higher process energies will lead to higher volumetric mass density, which as consequence will give better mechanical properties. The laser sintering can become a useful technology in manufacturing the medical components. Due to biocompatible properties of PA2200 and versatility of geometrical shape given by AM, spare parts and disposable surgical guides can be produced.

Acknowledgement: This research was partially funded by a grant Politehnica University of Timisoara, grant number GNaC2018 - ARUT, no.1363/01.02.2019.

\section{References}

1.CRISTACHE, C.M., GROSU, A.R., CRISTACHE, G., DIDILESCU, A.C., TOTU, E.E., Additive Manufacturing and Synthetic Polymers for Bone Reconstruction in the Maxillofacial Region, Mater. Plast., 55(4), 2018, 555-562.

2.MUHLFAY, G., FABIAN, Z., NEAGOE, R., HORVATH, K.U., Applications of 3D Planning, Plastic Materials and Additive Manufacturing in Functional Rehabilitationsin the Head and Neck Surgery Mater. Plast., 55(3), 2018, 431-433.

3.BRAILEANU, P.I., SIMION, I., BOU-SAID, B., PRISECARU, D.A., CRISAN, N., Custom Hip Stem Additive Prototyping Using Smart Materials, Mater. Plast., 57(2), 2020, 152-158.

4.ULMEANU, M.E., DOICIN, C.V., BAILA, D.I., RENNIE, A.E.W., NEAGU, C., LAHA, S., Comparative Evaluation of Optimum Additive Manufacturing Technology to Fabricate Bespoke Medical Prototypes of Composite Materials, Mater. Plast., 52(3), 2015, 416-422.

5.DAHAKE, S., KUTHE, A., MAWALE, M., Precision of customized surgical osteotomy guide (CSOG) in mandibular reconstruction with a customized implant. Rapid Prototyping Journal, 2019, Vol. 25 No. 10, pp. 1601-1623

6.POPESCU D., A. ZAPCIU, C. AMZA, F. BACIU, R. MARINESCU, FDM process parameters influence over the mechanical properties of polymer specimens: A review, Polymer Testing (2018), 69, 157-166

7.D. POPESCU, D. LAPTOIU, Rapid prototyping for patient-specific surgical orthopaedics guides: A systematic literature review, Proceedings of the Institution of Mechanical Engineers, Part H: Journal of Engineering in Medicine, 2016, 230(6), 495-515. 
8.ANTONIAC, I., MICULESCU, F, COTRUT, C., FICAI, A. , RAU, J.V. ,GROSU, E., ANTONIAC, A., TECU, C. CRISTESCU, I., Controlling the degradation rate of biodegradable Mg-Zn-Mn alloys for orthopedic applications by electrophoretic deposition of hydroxyapatite coating, Materials, (13), 2, 2020, 263.

9.RONTESCU, C., CICIC, D. T, BOGATU, A.M., AMZA C.Gh., CHIVU O. R, Research Regarding the Analysis of the Samples Used for Prosthetics and Medical Instruments Obtained by Sintering,

Rev. Chim., 68(9), 2017, 2114-2116.

10.PASCU, N.E., ARION, A.F., DOBRESCU, T., CARUTASU, N.L., Fused Deposition Modeling Design Rules for Plastics, Mater. Plast., 52(2), 2015, 141-143.

11.GUIDO, A.O.A., DETMAR, Z., On design for additive manufacturing: evaluating geometrical limitations. Rapid Prototyping J. 2015, 21, 662-670

12.LINUL, E.; MARSAVINA, L.; STOIA, D.I., Mode I and II fracture toughness investigation of LaserSintered Polyamide. Theoretical and Applied Fracture Mechanics, 2020, 106.

13.MARSAVINA, L., STOIA, D. I. Flexural properties of selectively sintered polyamide and Alumide. Mat Design Process Comm. 2020: 2; e 112. https://doi.org/10.1002/mdp2.112.

14.ANTONIAC, I., POPESCU, D., ZAPCIU, A., ANTONIAC, A., MICULESCU, F., MOLDOVAN, Magnesium filled polylactic acid (PLA) material for filament based 3D printing, Materials, 12, Issue 5, $2019,719$.

15.SOVER, A., MARZYNKEVITSCH, S., MUNACK, B., Processing Conditions of Expandable Graphite in PP and PA Matrix and their Performance, Mater. Plast., 55(4), 2018, 517-510.

16.MOUSA, A.A. Experimental investigations of curling phenomenon in selective laser sintering process. Rapid Prototyping J. 2006, 22, 405-415.

17.GRIESSBACH, S., LACH, R., GRELLMANN, W. Structure property correlations of laser sintered nylon 12 for dynamic dye testing of plastic parts. Polym. Test. 2010, 29, 1026-1030.

18.YEONG, W.Y., CHUA, C.K., Implementing Additive Manufacturing for Medical Devices: A Quality Perspective. In Proceedings of the $6^{\text {th }}$ International Conference on Advanced Research in Virtual and Rapid Prototyping, Leiria, Portugal, 1-5 October 2013, Taylor \& Francis, 2014; pp.115-120.

19.LIENEKE, T., DENZER, V., GUIDO, A., ADAM, O., ZIMMER, D., Dimensional tolerances for additive manufacturing: Experimental investigation for Fused Deposition Modeling. Elsevier Procedia CIRP 2016, 43, 286 - 291.

20.ES-SAID, O.S., FOYOS, J., NOORANI, R., MENDELSON, M., MARLOTH, R., PREGGER, B.A., Effect of layer orientation on mechanical properties of rapid prototyped samples. Mater. Manuf. Process., 2000, 15, 107-122.

21.MOUSA, A.A., Experimental investigations of curling phenomenon in selective laser sintering process. Rapid Prototyping J. 2006, 22, 405-415.

22.GRIESSBACH, S., LACH, R., GRELLMANN, W., Structure-property correlations of laser sintered nylon 12 for dynamic dye testing of plastic parts. Polym. Test., 2010, 29, 1026-1030.

23.LIENEKE, T., DENZER, V., GUIDO, A., ADAM, O., ZIMMER, D., Dimensional tolerances for additive manufacturing: Experimental investigation for Fused Deposition Modeling. Procedia CIRP 2016, 43, 286-291.

24.NUÑEZ, P.J., RIVAS, A., GARCIA-PLAZA, E., BEAMUD, E., SANZ-LOBERA, E., Dimensional and surface texture characterization in Fused Deposition Modelling with ABS plus. Procedia Engineering 2015, 132, 856-863.

25.DANG, A., ZHAO, Z., TANG, C., FANG, C., KONG, S., KHAN, M., LI, T., ZHAO, T.; LI, H., Effect of Phenolic Resin on Micropores Development in Carbon Foam with High Performance. Materials 2019, 12, 1213.

26.MENGQI, Y., BOURELL, D. Orientation effects for laser sintered polyamide optically translucent parts. Rapid Prototyping J.2016, 22, 97-103. 
27.GALANTUCCI, M., BODI, I., KACANI, J., LAVECCHI, F., Analysis of dimensional performance for a 3D open-source printer based on fused deposition modeling technique. Procedia CIRP 2015, 28, 82-87.

28.GOODRIDGE, R.D., TUCK, C.J., HAGUE, R.J.M., Laser sintering of polyamides and other polymers. Prog. Mater. Sci. 2012, 57, 229-267.

29.PILIPOVIĆ, A.; BRAJLIH, T.; DRSTVENŠEK, I., Influence of processing parameters on tensile properties of SLS polymer product. Polymers 2018, 10, 1208.

30.DIZON, J.R.C.; ESPERA, A.H.; CHEN, Q.; ADVINCULA, R.C., Mechanical characterization of 3D-printed polymers, Addit. Manuf. 2018, 20, 44-67.

31.RIVIS, M., PRICOP, M., TALPOS, S, CIOCOIU, R. ANTONIAC, I., GHEORGHITA, D., TRANTE, O., MOLDOVAN, H., GRIGORESCU, G., SECELEANU, V., MOHAN, A. Influence of the Bone Cements Processing on the Mechanical Properties in Cranioplast, Rev. Chim., 69(4), 2018, 990993.

32.TREVISAN, F.; CALIGNANO, F.; LORUSSO, M.; PAKKANEN, J.; AVERSA, A.; AMBROSIO, E.P.; LOMBARDI, M.; FINO, P.; MANFREDI, D., On the Selective Laser Melting (SLM) of the AlSi10Mg Alloy: Process, Microstructure, and Mechanical Properties. Materials 2017, 10, 76.

33.MORONI, G.; PETRO, S.; POLINI, W., Geometrical product specification and verification in additive manufacturing. CIRP Annals - Manufacturing Technology 2017, 66, 157-160.

34.BORZAN, C.Ş., DUDESCU, M.C., BERCE, P., Bending and compression tests for PA 2200 parts obtained using Selective Laser Sintering method. In $4^{\text {th }}$ International Conference on Computing and Solutions in Manufacturing Engineering - CoSME'16, 2017, 94, pp 1-8.

35.PALUMBO, B.; DEL RE, F.; MARTORELli, M.; LANZOTTI, A.; CORRADO, P., Tensile Properties Characterization of AlSi10Mg Parts Produced by Direct Metal Laser Sintering via Nested Effects Modeling. Materials 2017, 10, 144.

36.***EOS GmbH Product information. Available online: www.eos.info/material-p (accessed on 25 February 2020).

37.***Biological evaluation of medical devices- Part 1: Evaluation and testing within a risk management process; ISO 10993-1:2018; International Organization for Standardization; 1214 Vernier, Geneva, Switzerland, 2018, pp. 41.

38.***Plastics - Differential scanning calorimetry (DSC) - Part 1: General principles, ISO 113571:2016,1214 Vernier, Geneva, Switzerland, 2016, pp.33

39.STOIA, D.I., LINUL, E. MARSAVINA, L., Influence of manufacturing parameters on mechanical properties of porous materials by Selective Laser Sintering, Materials 2019, 12, 871.

40.STOIA, D.I., MARSAVINA, L, LINUL, E. Correlations between process parameters and outcome properties of Laser-Sintered Polyamide. Polymers, 11 (2019) 1850.

41.STOIA, D.I., MARSAVINA, L., Effect of Aluminum Particles on the Fracture Toughness of Polyamide-based Parts Obtained by Selective Laser Sintering (SLS), Procedia Structural Integrity 18 (2019) 163-169

Manuscript received: 12.03 .2020 